\title{
Associations between Anxiety and Depression Symptoms and Medical Care Avoidance during COVID-19
}

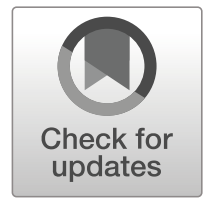

J Gen Intern Med 35(11):3406-8

DOI: $10.1007 / \mathrm{s} 11606-020-06156-8$

(C) Society of General Internal Medicine 2020

\section{INTRODUCTION}

Since the outbreak of the novel coronavirus disease 2019 (COVID-19) pandemic, emergency health care utilization has acutely declined by $23 \%$ for heart attacks, $20 \%$ for strokes, and $10 \%$ for hyperglycemic crises. ${ }^{1}$ Ambulatory visits have also declined by nearly $60 \%{ }^{2}$ The lack of health care utilization is concerning as it may result in significant medical complications resulting from untreated medical problems. ${ }^{1}$ Little is known about what is driving these declines in health care utilization. A study from Italy suggested that fear of COVID-19 infection may be one such factor. ${ }^{3}$ Recent research has documented pervasive anxiety and depression during the COVID-19 pandemic. ${ }^{4,5} \mathrm{We}$ conducted this study to estimate the association between mental health symptoms and medical care avoidance among US adults.

\section{METHODS}

We analyzed data from June 11-June 16, 2020, of the weekly, cross-sectional Household Pulse Survey (HPS; $n=73,472$ ) which is conducted by the US Census $\mathrm{Bu}$ reau in collaboration with five other federal agencies to produce data on the social and economic impacts of COVID-19 among adults in the USA. The HPS questionnaire was reviewed by independent experts at the Center for Behavioral Science Methods, as well as the Demographic Directorate and subject matter representatives from the five partner federal agencies. To gather the sample, HPS used the Census Bureau's Master Address File as the primary sampling frame to collect responses from a large sample that is sufficient for the anticipated low responses rates. The Census Bureau used the online platform Qualtrics as the primary data collection method. See the Census Bureau website (https://www.census.gov/

Prior Presentations The results from this study have not been presented previouslu.

Received July 20, 2020

Accepted August 14, 2020

Published online September 1, 2020 householdpulsedata) for more information and access to publicly available data.

We fitted modified multivariable Poisson regression models to estimate the associations between four mental health symptoms (nervous, anxious, or on edge; not being able to stop or control worrying; little interest or pleasure in doing things; feeling down, depressed, or hopeless) in the past 7 days and medical care avoidance (delayed medical care; needed non-coronavirus medical care but did not get it) due to the coronavirus pandemic in the past 4 weeks. The use of robust estimates of variance permits straightforward interpretation of the exponentiated regression coefficients as risk ratios. We adjusted for potential confounding by age, sex, race/ethnicity, income, education, employment loss, and marital status. Nonresponse sample weighing was applied. Analyses were conducted using Stata 15.1.

\section{RESULTS}

Demographic and descriptive results are displayed in Table 1. Individuals who experience all four symptoms of anxiety and depression had higher adjusted relative risk ratios of delayed medical care and not receiving needed non-coronavirus medical care, after adjustment for potential confounders (Table 2). Individuals who were nervous, anxious, or on edge in the past 7 days had the highest adjusted relative risk ratio of delayed medical care (1.95, 95\% CI 1.83-2.09) and the highest adjusted relative risk ratio of not receiving needed non-coronavirus medical care $(2.08,95 \%$ CI 1.93-2.25).

\section{DISCUSSION}

In this population-based study of US adults from June 11-16, 2020 , we show that mental health symptoms are strongly correlated with medical care avoidance amidst the COVID19 pandemic. Our results revealed significantly higher adjusted relative risk ratios of medical care avoidance among US adults who experience common symptoms of anxiety and depression. Importantly, our results show that individuals who experience these symptoms are more likely to avoid seeking non-coronavirus medical care despite needing it, which is concerning as delayed medical care may result in significant adverse short- and long-term health outcomes for many conditions. ${ }^{1}$ 
Table 1 Weighted Sample Characteristics of Week 7 of US Census Household Pulse Survey $(n=73,472)$

\begin{tabular}{|c|c|}
\hline & Mean $\pm \mathrm{SE} / \%$ \\
\hline Age & $48.09 \pm 0.20$ \\
\hline \multicolumn{2}{|r|}{$70.07+0.20$} \\
\hline Female & 51.6 \\
\hline \multicolumn{2}{|l|}{ Race/ethnicity } \\
\hline Hispanic or Latino (may be of any race) & 16.9 \\
\hline White alone, not Hispanic & 62.8 \\
\hline Black alone, not Hispanic & 11.2 \\
\hline Asian alone, not Hispanic & 5.0 \\
\hline Two or more races + other races, not Hispanic & 4.1 \\
\hline \multicolumn{2}{|l|}{ Income } \\
\hline Less than $\$ 25,000$ & 16.5 \\
\hline$\$ 25,000-\$ 34,999$ & 12.0 \\
\hline$\$ 35,000-\$ 49,999$ & 12.5 \\
\hline$\$ 50,000-\$ 74,999$ & 18.1 \\
\hline$\$ 75,000-\$ 99,999$ & 12.9 \\
\hline$\$ 100,000-\$ 149,999$ & 14.8 \\
\hline$\$ 150,000-\$ 199,999$ & 6.4 \\
\hline$\$ 200,000$ and above & 6.7 \\
\hline \multicolumn{2}{|l|}{ Education } \\
\hline Bachelor's degree or higher & 30.4 \\
\hline \multicolumn{2}{|l|}{ Employment loss, past 7 days } \\
\hline Yes & 47.8 \\
\hline \multicolumn{2}{|l|}{ Marital status } \\
\hline Not married & 55.1 \\
\hline \multirow{2}{*}{\multicolumn{2}{|c|}{$\begin{array}{l}\text { Medical care avoidance } \\
\text { Delaved medical care due to coronavirus, } 4 \text { weeks }{ }^{\dagger}\end{array}$}} \\
\hline & \\
\hline Yes & 41.0 \\
\hline \multicolumn{2}{|l|}{ Needed non-coronavirus medical care but did not get it, past 4 weeks } \\
\hline Yes & 32.2 \\
\hline \multicolumn{2}{|l|}{ Mental health symptoms } \\
\hline \multicolumn{2}{|l|}{ Nervous, anxious, or on edge, past 7 days ${ }^{\S}$} \\
\hline & 65.0 \\
\hline \multicolumn{2}{|l|}{ Not being able to stop or control worrying, past 7 days" } \\
\hline Any days & 56.1 \\
\hline \multicolumn{2}{|l|}{ Little interest or pleasure in doing things, past 7 days II $^{\text {I }}$} \\
\hline Any days & 53.3 \\
\hline \multicolumn{2}{|l|}{ Feeling down, depressed, or hopeless, past 7 days ${ }^{\#}$} \\
\hline Any days & 52.2 \\
\hline
\end{tabular}

June 11-June 16, 2020

+"At any time in the last 4 weeks, did you DELAY getting medical care because of the coronavirus pandemic?"

t "At any time in the last 4 weeks, did you need medical care for something other than coronavirus, but DID NOT GET IT because of the coronavirus pandemic?"

\$ "Over the last 7 days, how often have you been bothered by the following problems ... Feeling nervous, anxious, or on edge?"

" "Over the last 7 days, how often have you been bothered by the following problems ... Not being able to stop or control worrying?"

" "Over the last 7 days, how often have you been bothered by ... having little interest or pleasure in doing things?"

\#"Over the last 7 days, how often have you been bothered by ... feeling down, depressed, or hopeless?"

Our results provide support for accurate and effective translation of knowledge to the public about the risks and benefits of seeking needed medical care during the ongoing COVID19 pandemic. Of particular importance is the expansion of health insurance policies to cover telehealth services ${ }^{6}$ and continued efforts to implement telehealth services to address non-emergency medical concerns. Additionally, a continued increase in telepsychiatry and telemental health services is needed to assist US adults in managing mental health symptoms for the duration of the COVID-19 pandemic.

Table 2 Adjusted Relative Risk Ratios of Mental Health Symptoms and Medical Care Avoidance

\begin{tabular}{|c|c|c|c|c|}
\hline & Delayed medical care* & $p$ & Did not get medical care ${ }^{a}$ & $p$ \\
\hline & $\begin{array}{l}\text { Adjusted relative risk ratio } \\
(95 \% \mathrm{CI})\end{array}$ & & $\begin{array}{l}\text { Adjusted relative risk ratio } \\
(95 \% \mathrm{CI})\end{array}$ & \\
\hline Nervous, anxious, or on edge, past 7 days & $1.95(1.83-2.09)$ & 0.001 & $2.08(1.93-2.25)$ & 0.001 \\
\hline Not being able to stop or control worrying, past 7 days & $1.83(1.73-1.94)$ & 0.001 & $2.05(1.92-2.00)$ & 0.001 \\
\hline Little interest or pleasure in doing things, past 7 days & $1.69(1.60-1.79)$ & 0.001 & $1.90(1.78-2.03)$ & 0.001 \\
\hline Feeling down, depressed, or hopeless, past 7 days & $1.67(1.58-1.76)$ & 0.001 & $1.89(1.77-2.02)$ & 0.001 \\
\hline
\end{tabular}

*Each column displays estimates from a single multivariable Poisson regression model with additional covariate adjustment for age, sex, racelethnicity, income, education, employment loss, and marital status. As described by Zou (Am J Epidemiol. 2004;159:702-706), the modified Poisson model permits interpretation of the exponentiated regression coefficients as risk ratios rather than incidence rate ratios. 
Acknowledgments: We would like to thank Samuel Benabou for providing editorial assistance.

Kyle T. Ganson, $\mathrm{PhD}, \mathrm{MSW}^{1}$

Sheri $D$. Weiser, $M D, M P H^{2}$

Alexander C. Tsai, $M D^{3,4}$

Jason M. Nagata, MD, MSc ${ }^{5}$

${ }^{1}$ Factor-Inwentash Faculty of Social Work, University of Toronto,

Toronto, ON, Canada

${ }^{2}$ Division of HIV, Infectious Diseases and Global Medicine, School of Medicine, University of California, San Francisco,

San Francisco, CA, USA

${ }^{3}$ Center for Global Health and Mongan Institute, Massachusetts General Hospital,

Boston, MA, USA

${ }^{4}$ Harvard Medical School,

Boston, MA, USA

${ }^{5}$ Division of Adolescent and Young Adult Medicine, Department of Pediatrics, University of California, San Francisco,

San Francisco, CA, USA

Corresponding Author: Kyle T. Ganson, PhD, MSW; FactorInwentash Faculty of Social Work, University of Toronto, Toronto, ON, Canada (e-mail: kyle.ganson@utoronto.ca).

Funding Information Dr. Tsai reports salary support from the Sullivan Family Foundation.

\section{Compliance with Ethical Standards:}

Conflict of Interest: The authors declare that they do not have a conflict of interest.

\section{REFERENCES}

1. Lange SJ, Ritchey MD, Goodman AB, et al. Potential Indirect Effects of the COVID-19 Pandemic on Use of Emergency Departments for Acute LifeThreatening Conditions - United States, January-May 2020. MMWR Morb Mortal Wkly Rep. 2020;69(25):795-800. https://doi.org/10.15585/mmwr. mm6925e2

2. Mehrotra A, Chernew M, Linetsky D, Hatch H, Cutler D. The Impact of the COVID-19 Pandemic on Outpatient Visits: A Rebound Emerges. The Commonwealth Fund. https://doi.org/10.26099/ds9e-jm36

3. Lazzerini M, Barbi E, Apicella A, Marchetti F, Cardinale F, Trobia G. Delayed access or provision of care in Italy resulting from fear of COVID19. Lancet Child Adolesc Heal 2020;4(5):e10-e11. https://doi.org/10. 1016/S2352-4642(20)30108-5

4. Rajkumar RP. COVID-19 and mental health: A review of the existing literature. Asian J Psychiatr. 2020;52(March). https://doi.org/10.1016/j. ajp.2020.102066

5. Torales J, O'Higgins M, Castaldelli-Maia JM, Ventriglio A. The outbreak of COVID- 19 coronavirus and its impact on global mental health. Int $J$ Soc Psychiatry 2020;66(4):317-320. https://doi.org/10.1177/ 0020764020915212

6. Smith AC, Thomas E, Snoswell CL, et al. Telehealth for global emergencies: Implications for coronavirus disease 2019 (COVID-19). J Telemed Telecare 2020;26(5):309-313. https://doi.org/10.1177/ $1357633 X 20916567$

Publisher's Note: Springer Nature remains neutral with regard to jurisdictional claims in published maps and institutional affiliations. 